\title{
Giant Cell Arteritis: Real-life Experience
}

\section{Peter M. Villiger ${ }^{1}$ (ID}

Giant cell arteritis (GCA), the most frequent form of vasculitis in the elderly, still poses questions regarding optimal treatment. Because of the risk of permanent vision loss, the revised European League Against Rheumatism recommendation of 2018 stresses that glucocorticoid (GC) therapy should start as soon as a diagnosis of GCA is strongly suspected. ${ }^{1}$ This initiates a GC exposure with a high risk of side effects such as fractures and infections.

Two randomized controlled trials (RCTs) have shown that blockade of the interleukin (IL)-6 pathway using tocilizumab (TCZ), a monoclonal antibody binding the IL-6 receptor chain, leads to a significant reduction of cumulative GC and a reduced relapse rate. ${ }^{2,3}$ In addition, $30-50 \%$ of patients stayed in remission over more than 2 years after discontinuation of a 12-month treatment with TCZ. These data strongly suggest a very profound effect of $\mathrm{TCZ}$ on pathogenic events.

In this issue of The Journal of Rheumatology, the retrospective observational multicenter study by Clément, et al meticulously analyzes the performance of TCZ in the real-world setting. ${ }^{4} \mathrm{The}$ primary focus is on relapse rate, but the authors also report on safety and long-term outcome. Relapse is defined as therapeutic escalation. In brief, time from diagnosis to first TCZ administration (i.e., inclusion in the study) was 511 days, the relapse rate before inclusion was $72 \%$ (1.26/patient-yr), and the cumulative steroid prescription was $9.4 \mathrm{~g} /$ year. After inclusion, patients were followed over 842 days; cumulative GC prescription dropped to $2.1 \mathrm{~g} /$ year. Twenty-six of the 43 discontinued TCZ after a median of 279 days. Sixty percent of patients received a concomitant treatment with methotrexate.

The study adds important real-world data that support the findings of the RCTs regarding a steroid-sparing effect and reduction of relapses. Importantly, the remission rate after termination of treatment was lower than reported in the long-term data of the RCTs - possibly due to long-standing disease activity in the majority of patients.

${ }^{1}$ P.M. Villiger, MD, Full Professor of Rheumatology and Clinical Immunology em, University of Bern, Switzerland.

$P M V$ receives speaker, advisory fees, and research support from Roche, MSD, AbbVie, Pfizer, Novartis, Grünenthal, Amgen, Sanofi, Chugai, BMS, and Gilead. Address correspondence to Dr. P. Villiger, Medical Center Monbijou, 3011 Bern, Switzerland.Email:Peter.villiger@hin.ch.

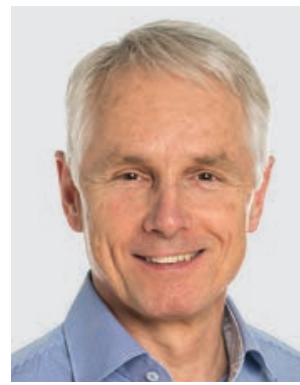

Noteworthy is the fact that C-reactive protein levels rose under TCZ treatment in $60 \%$ of relapses. The authors report that TCZ doses were gradually reduced in cases of stable remission. This reduction may explain the findings and nicely shows a dose effect of TCZ on the suppression of the acute-phase response.

Four variables for predicting relapse were detected (i.e., start of TCZ later than 6 months after diagnosis, need of GC $\geq 5 \mathrm{mg}$ prednisone, high relapse rate $[>0.8 / \mathrm{yr}]$, no ischemic signs at diagnosis). The fourth variable is a surprise as this is counterintuitive and not supported by earlier data about vision loss. As it stands, the identified variables may argue for an earlier introduction of TCZ. A finding of concern is the high mortality rate. Three elderly patients under TCZ treatment died because of infection.

This may be mere chance, but it suggests that age and concomitant GC treatment pose an important increase in mortality risk, which is higher as compared to data in patients with rheumatoid arthritis.

In summary, the study of Clément, et al confirms a clinically important GC-sparing effect of TCZ and a significantly reduced relapse rate under IL- 6 inhibition therapy. ${ }^{4}$ As compared to the long-term data of the $2 \mathrm{RCTs},{ }^{2,3}$ relapse rate after termination of TCZ treatment was higher. Further, the high number of lethal infections has to raise awareness. Taken together, this study ${ }^{4}$ supports early use of TCZ and may suggest a more systematic and rapid reduction of GCs in order to reduce side effects.

\section{REFERENCES}

1. Villiger PM, Adler S, Kuchen S, Wermelinger F, Dan D, Fiegeet V, et al. Tocilizumab for induction and maintenance of remission in giant cell arteritis: a phase 2, randomised, double-blind, placebo-controlled trial. Lancet 2016;387:1921-7.

2. Stone JH, Tuckwell K, Dimonaco S, Klearman M, Aringer M, Blockmans D, et al. Trial of tocilizumab in giant-cell arteritis. N Engl J Med 2017;377:317-28.

3. Hellmich B, Agueda A, Monti S, Buttgereit F, de Boysson H, Brouwer E, et al. 2018 Update of the EULAR recommendations for the management of large vessel vasculitis. Ann Rheum Dis 2020;79:19-30.

4. Clément J, Duffau P, Constans J, Schaeverbeke T, Viallard JF, Barcat $\mathrm{D}$, et al. Real-world risk of relapse of giant cell arteritis treated with tocilizumab: a retrospective analysis of 43 patients. J Rheumatol 2021;48:1435-41.

\section{See Tocilizumab in GCA, page 1435}

